\title{
A stochastic approach for integrating market and technical uncertainties in economic evaluations of petroleum development
}

\author{
Changhyup Park ${ }^{1 *}$, Joe M. Kang ${ }^{2}$ and Taewoong Ahn² \\ ${ }^{1}$ BK21 Research Division for Energy Resources, Seoul National University, Seoul 151-742, Republic of Korea \\ ${ }^{2}$ Division of Energy Systems Engineering, Seoul National University, Seoul 151-742, Republic of Korea
}

\begin{abstract}
The paper presents a stochastic and economic analysis for petroleum development under uncertain market and technical environments. Mean-reversion with jumps for price forecasting is used to consider market uncertainty, while various scenarios for the reservoir properties and cost are employed to consider technical uncertainty. Monte Carlo simulation is carried out to obtain the feasible range of net present values and internal rates of return. The influence of stochastic parameters is examined through correlation coefficients.

The stochastic approach yields more reliable evaluation and effectively investigates the characteristics of development. The integration of uncertainties and contractual terms results in an irregular tendency in the future cash flow and reveals that a larger reserve does not guarantee a greater profit. The reserve and the well rate affect the economic values whereas the parameters for price prediction don't. The research confirms the necessity of qualifying uncertainties for realistic decision-making at the initial stage of development.
\end{abstract}

Key words: Uncertainty, petroleum development, decision-making, stochastic approach, mean reversion with jumps

\section{Introduction}

Investment decisions in petroleum development are frequently made under significant technical, political, and market uncertainties that arise from limitations of current knowledge. Technical uncertainty decreases over time and is related to reserves, production rates, the probability of finding petroleum accumulation, etc., while market uncertainty, which refers to future oil and gas price, remains constant over the lifetime of petroleum development. As investors are unable to eliminate these complex uncertainties, it is necessary to quantify these uncertainties for making better decisions and allocating the operator's capital with increased efficiency(Olsen et al, 2005). It is difficult to evaluate political risk but an evaluation has done so by considering the larger Weighted Average Cost of Capital(WACC) in politically unstable countries.

The price model is important for evaluating the revenues or the project values. Stochastic processes for forecasting the oil-price are classified into: Geometric Brownian Motion(GBM); Mean Reversion(MR); and Mean Reversion with Jumps(MRJ). Contrary to MR, GBM assumes that price changes are independent of one another. The idea of MR

\footnotetext{
* Corresponding author. email: chpark@petro.snu.ac.kr
} Received January 19, 2009 is that both high and low prices are temporary and that the price will tend to converge to a mean equilibrium price over time. MRJ is an extension of MR that features the addition of occasional jumps in price over and above typical fluctuations. From the viewpoint of economic statistics, many researchers have verified MRJ to be a better and a more reliable model than the others, because it considers the normal events that are modeled through MR as well as abnormal events that cause jumps in the oil-price(Dias and Rocha, 1998; Pelet, 2003; Staber, 2006; Al-Harthy, 2007; Begg and Smit, 2007). Al-Harthy(2007) analyzed the effect of stochastic oil-price models, as described above, on petroleum development. He concluded that MRJ captured the uncertainty range of NPV better than the others and that the effect of volatility of the price could be insignificant on MRJ in contrast with GBM. These results have confirmed the usefulness and applicability of MRJ in petroleum development.

On the other side, technical uncertainty for petroleum development is related to the reservoir properties such as the reserve volume, the production rate, and the cost of development. Hultzch et al(2008) carried out Monte Carlo simulation including the statistical variation of reservoir properties for strategic decision-making.

A petroleum project has its own specialized contract, which is classified into two types. The first is the royalty-tax system. The other is the production-sharing contract(PSC) (Johnston, 1994). In the royalty-tax system, the producer 
pays only the royalty and the cooperation tax while s/he is entitled to a portion of the production that is based on various contractual terms as specified in the PSC. The cash-flow in the former(i.e. royalty-tax concessionary) may be directly proportional to price and cost variations whereas it is not so in the latter(i.e. PSC) because of various contractual terms such as the ceiling on the cost recovery, production-sharing ratio with a sliding scale rule, and ring fencing. Furthermore, the government, as the block holder, acts to make the fiscal terms of PSC worse for participants, as a result of which the partners do not achieve a significant return. The terms that bind a contractor can relatively reduce the effect of price fluctuations and result in higher returns to the lease-hold position.

Previous studies, as described above, have considered these uncertainties separately and focused on a simplified cash-flow model that ignores the various effects of fiscal terms. This approach might result in unreliable evaluation of particular projects, although it could explain the general market trend. To evaluate the petroleum assets realistically in an uncertain environment, we developed a stochastic process that incorporates oil-price changes, the PSC, and the reservoir properties following statistical distributions. A correlation coefficient is used to examine the effect of stochastic parameters on the asset value.

\section{Market uncertainty: stochastic oil price}

The oil-price represents the market uncertainty. One of the key characteristics of oil-prices that follow MRJ is that their volatility appears to consist of normal fluctuations along with large changes that are rare (Begg and Smit, 2007). The normal fluctuation follows a mean reversion process that tends to be continually pulled towards a long-tem price while the fluctuation occurs sporadically in the form of jumps.
MRJ considers the following Arithmetic Ornstein-Uhlenbeck process with discrete jumps for the stochastic oil-price, $P$ (Dixit and Pindyck, 1994; Dias and Rocha, 1998; Pelet, 2003).

$$
\frac{\mathrm{d} P}{P}=\eta(\bar{P}-P) \mathrm{d} t+\sigma \mathrm{d} z+\mathrm{d} q
$$

Where, $\frac{\mathrm{d} P}{P}$ refers to the relative change in the price; $\eta(\bar{P}-P) \mathrm{d} t$, $\sigma \mathrm{d} q$ and $\mathrm{d} q$ refers to the expected trend of the mean reversion, the random volatility effect, and the jump effect, respectively. The values of $\sigma \mathrm{d} q$ and $\mathrm{d} q$ are uncertain. $\eta(\bar{P}-P) \mathrm{d} t$, is made to revert to the equilibrium price $(\bar{P})$ over time. $\eta, \sigma$, and $\mathrm{d} z$ respectively imply the reversion speed, the price volatility, and the Wiener increment. The reversion speed, $\eta=0$ corresponds to a simple Brownian motion that follows a random walk. When $\eta=0.5, P$ makes only small and short-lived excursions away from $\bar{P}$ (Dixit and Pindyck, 1994). The price volatility, $\sigma$ poses the greatest challenge with regard to the determination of the proper value and can be estimated by the logarithmic flow, the proxy approach and Monte Carlo simulation (Kodukula and Papudesu, 2006). This work determines $\sigma$ as the value of the standard deviation of $\left(\ln P_{t}-\ln P_{t-1}\right)$ under the assumption of a logarithmic price trend. The term for jumps in the price $(\mathrm{d} q)$ is assumed to be independent of $\mathrm{d} z$ and consists of a frequency of jumps per unit time $(\lambda)$ and a size $(\Phi)$, as shown in Eq. (2).

$$
\mathrm{d} q=\left\{\begin{array}{cc}
0, & \text { with probability }(1-\lambda) \mathrm{dt} \\
\Phi-1, & \text { with probability } \lambda \mathrm{dt}
\end{array}\right.
$$

Eq. (1) can be solved by simulating Eq. (3) (Dias and Rocha, 1998).

$$
P_{t}=\exp \left[\ln \left(P_{t-1}\right) e^{-\eta \Delta t}+\ln (\bar{P})\left(1-e^{-\eta \Delta t}\right)-\left(1-e^{-2 \eta t}\right) \frac{\sigma^{2}}{4 \eta}+\sigma \sqrt{\frac{1-e^{-2 \eta \Delta t}}{2 \eta}} N(0,1)+\mathrm{Jumps}\right]
$$

In Eq. (3), $N(0,1)$ refers to the random value that is extracted from the standard normal distribution. The term for jumping is either an increment or a decrement in the estimated oil price. A jump with size, $\Phi-1$ means the ratio of the current price to the previous-year price and occurs only at $\lambda<U(0 \sim 1) . U(0 \sim 1)$ is a random value between 0 and 1 that follows a uniform distribution. $\Phi$ is determined from a probability distribution function as shown in Eq. (4) and illustrated in Fig. 1(Pelet, 2003).

$$
\begin{aligned}
\operatorname{pdf}(\Phi) & =\frac{1}{2} \frac{1}{\sigma_{1} \sqrt{2 \pi}} \exp \left[-\frac{1}{2}\left(\frac{\Phi-m_{1}}{\sigma_{1}}\right)^{2}\right] \\
& +\frac{1}{2} \frac{1}{\sigma_{2} \sqrt{2 \pi}} \exp \left[-\frac{1}{2}\left(\frac{\Phi-m_{2}}{\sigma_{2}}\right)^{2}\right]
\end{aligned}
$$

In Eq. (4), $m_{1}=\frac{1}{2}, m_{2}=2, \sigma_{1}=\frac{1}{8}$ and $\sigma_{2}=\frac{2}{7}$. It has the same chance of being up or down for each

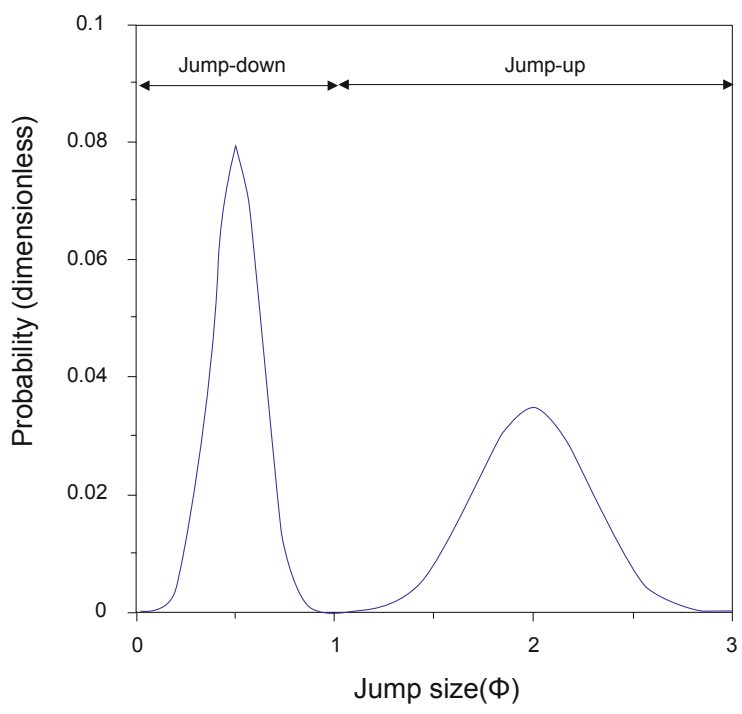

Fig. 1 Probability distribution function of jump size(Ф) 
cumulative-probability is 0.5 . The average jump size is greater than 1 and tends to cause the price to increase over a long enough duration because of the different variance of the jumps.

\section{Technical uncertainty: petroleum development}

The technical uncertainty of petroleum development covers the reserve, the production rate, and the cost of development. A typical production profile is illustrated in Fig. 2. It is broken down into three phases: build-up; plateau; and decline. The production in the first phase sharply increases from the commencement of the development or the completion of the construction of the facility. The production remains at the maximum value for a certain period; the plateau phase. As the reservoir pressure decreases, the production rate declines following a roughly exponential or hyperbolic decline curve. The reserve estimate exhibits considerable uncertainty in the initial stage of development although it can affect the maximum production rate per each well, the overall drilling cost, and the facility cost.

\section{Methodology}

The market and technical uncertainties are integrated independently into a discounted cash-flow model. To demonstrate the market uncertainty, MRJ makes a stochastic perturbation to generate the price trajectory. For the technical uncertainty, various production profiles is constructed along with Stock Tank Original Oil In Place (STOOIP), recovery factor, well rate, and discount factor in the production decline phase. In addition, it assumes that a facility cost varies as maximum production capacity.

The discounted cash-flow model is constructed by using

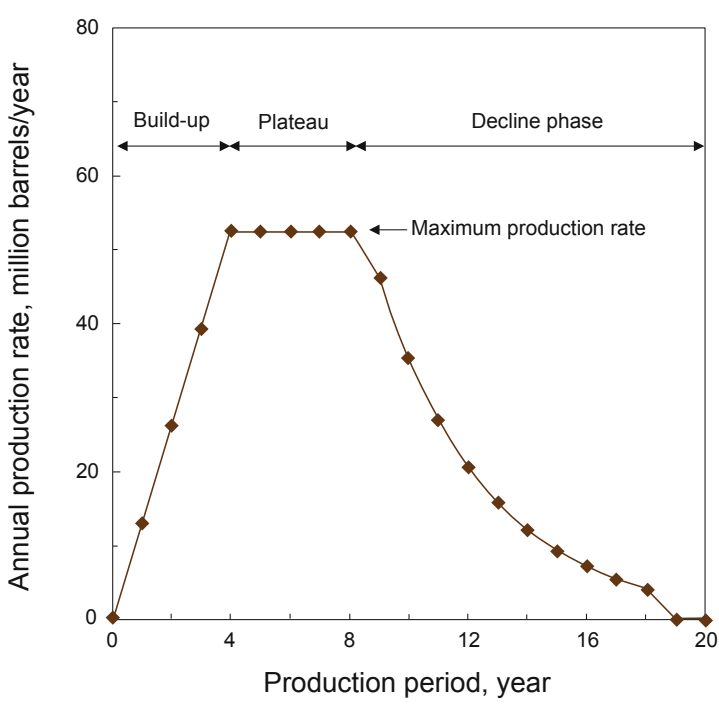

Fig. 2 Typical production profile of petroleum development

deterministic parameters. It is based on contractual terms of PSC including cost recovery, production bonus, profitsplit ratio, income tax, and depreciation. Table 1 shows the details of fiscal terms in this work. Various cash-flows are obtained by Monte Carlo simulation with 10,000 trials from appropriate and pre-specified statistical distributions (Table 1). The distributions of economic parameters such as the revenue, Net Present Value (NPV), and Internal Rate of Return (IRR) are obtained. The effects of the input parameters on the economic evaluation are investigated through correlation coefficients.

\section{Parameter estimation for price prediction}

The uncertain parameters for price prediction are the reversion speed $(\eta)$, the volatility $(\sigma)$, and the equilibrium oil-

Table 1 Fiscal terms of production sharing contact in this study

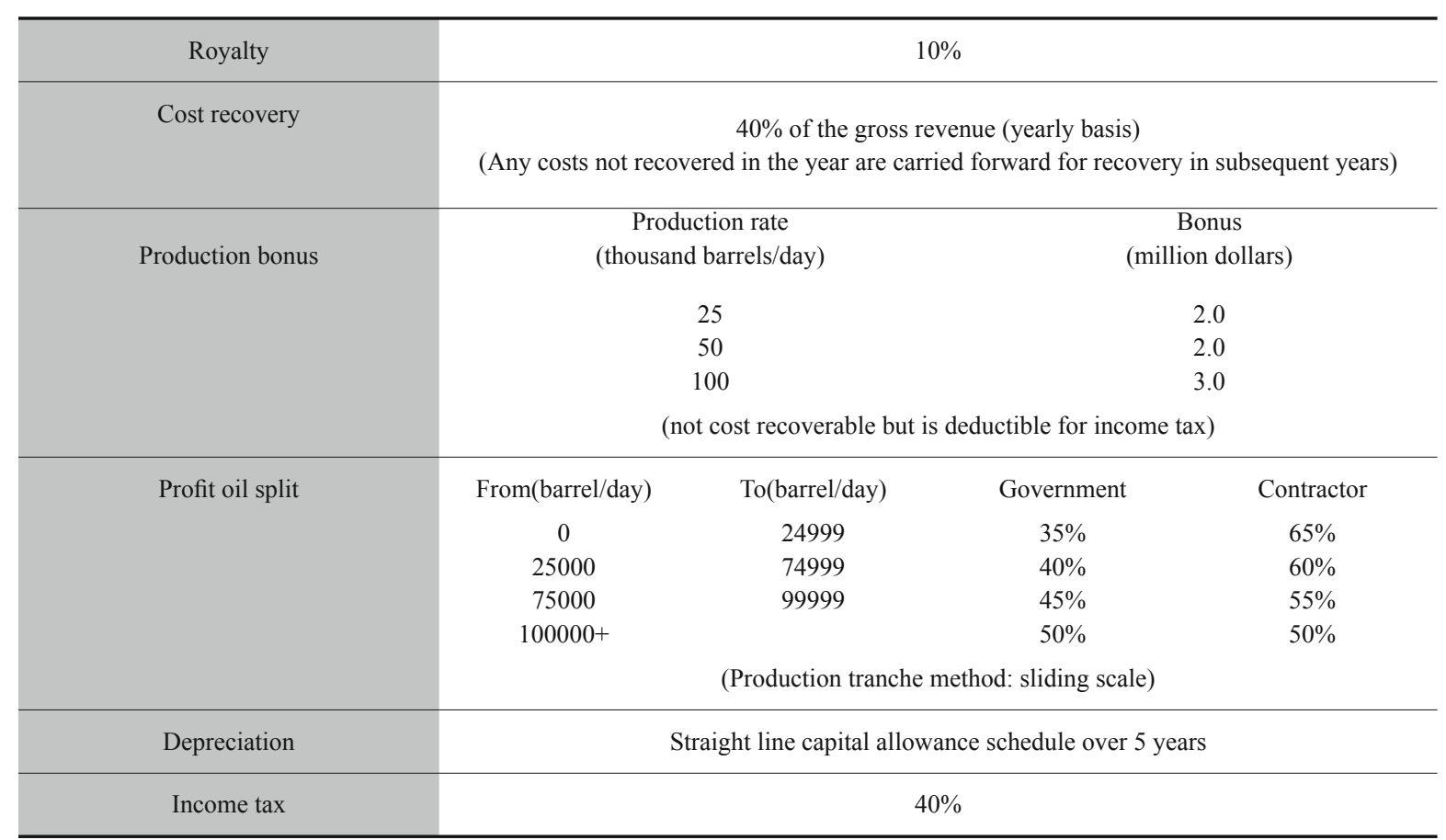


price $(\bar{P})$. The reversion speed $(\eta)$ and the volatility $(\sigma)$ can be estimated from historical data on price and the equilibrium oil price $(\bar{P})$ can be obtained from various projections. Fig. 3 shows the Brent price changes from 1989 to 2008 and Table 2 summaries some of the projections of oil-price in 2010-2030. Fig. 3 also shows the steep decline in the oil-price during the global financial crisis at the end of 2008. The annual volatility is 0.258 , the standard deviation of $\left(\operatorname{In} P_{t}-\operatorname{In} P_{t-1}\right)$.
Begg and Smit (2007) analyzed the oil-price over 18612006 and obtained the range of the reversion speed and the volatility on an annual basis. The reversion speed was 0.12 when all the oil-price data over 1861-2006 were considered and 0.19 when the recent data, i.e., from 1970 to 2006 were considered; the values of the annual volatility were 0.28 and 0.32 , respectively. The equilibrium price $(\bar{P})$ varies from $\$ 55 /$ barrel to $\$ 67 /$ barrel, as shown in Table 3.

Table 2 Projections of world oil prices in 2010-2030 (EIA, 2008)

\begin{tabular}{ccccccc}
\hline Projection & 2010 & 2015 & 2020 & 2025 & 2030 & \multicolumn{2}{c}{ Average } \\
\hline AEO2008 & 74.03 & 59.85 & 59.70 & 64.49 & 70.45 & 65.70 \\
GII & 68.25 & 61.40 & 54.80 & 48.20 & 45.70 & 55.67 \\
IEA & 59.03 & 57.30 & 58.87 & 60.43 & 62.00 & 59.53 \\
DB & 56.65 & 60.00 & 66.00 & 72.00 & 80.00 & 66.93 \\
SEER & 69.41 & 58.85 & 60.83 & 62.88 & 65.00 & 63.39 \\
\hline
\end{tabular}

Fig. 3 shows several historical jumps in price. This work used the fixed value, 0.125 for jump frequency as Pelet (2003) did, meaning jumps-up or -down would occur once in 8 years.

\section{Statistical distribution of technical parameters}

It assumes that the exploration drilling succeeds in finding an oil accumulation but the reserve, well rate, and profitability are indeterminate. STOOIP (million barrels), recovery factor $(\%)$, well rate (thousand barrels/day), decline rate (\%), and facility cost (million dollars) are uncertain from the view of technical uncertainty.

The volumetric value of the reserve is calculated by multiplying STOOIP with the recovery factor. The number of production wells is calculated through the maximum production rate (thousand barrels/day) divided by the well rate (thousand barrels/day). The annual production volume

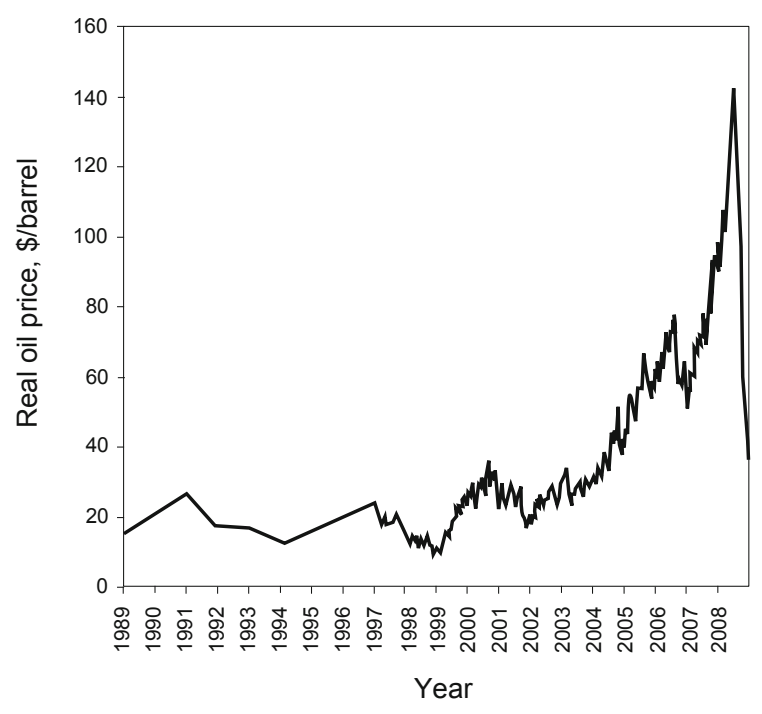

Fig. 3 Historical data of crude oil price from 1989 to 2008 is increased linearly for 3 years. The maximum production volume in the plateau period is $10 \%$ of the reserve. It starts to decline from $65 \%$ of the reserves where the production rate is expected to follow the exponential function (Eq. (5)).

$$
q_{t}=q_{t-1} e^{-D t}
$$

In Eq. (5), $q_{t}$ is the annual rate of production (million barrels/year) at time $t$ (year) and $D$ is the discount factor (dimensionless or \%) in the decline phase. The facility costs are separated into 7 different scenarios according to the maximum producing rate as shown in Table 1 . The development of the facility takes 4 years. On the contrary, other costs related with drilling and operating are fixed. It assumes that the development funds are raised without debt and WACC is $10 \%$ p.a. Table 3 summaries the parameters for both market and technical uncertainty used in the Monte Carlo simulation.

\section{Results and Discussion}

Fig. 4 shows one example of the oil-price trend generated by using MRJ and it explains the characteristics of reversion to the equilibrium price and the irregular, discrete jumps. 10,000 oil trends were generated separately. The individual net cash flow under the PSC terms is generated by inputting each trend and stochastic variables as given in Table 3. One example of the net cash flow is illustrated in Fig. 5. If one deterministic oil-price is used, the undiscounted cash-flow should be similar to the production profile in Fig. 2 except for the stage of development of the facility (i.e. the initial four years). However, Fig. 5 reveals the effect of various oil prices by showing the irregular shape that corresponds to the value of the oil-price.

A hurdle rate of $15 \%$ is assumed as the minimum IRR that must be met for a company to undertake this development. 
Table 3 Input parameters for Monte Carlo simulation

\begin{tabular}{|c|c|c|}
\hline Input parameter & \multicolumn{2}{|c|}{ Value or distribution type } \\
\hline \multicolumn{3}{|l|}{ Market uncertainty } \\
\hline Equilibrium oil price $(\bar{P})$ & \multicolumn{2}{|l|}{$\mathrm{N}(62.25,7.56)$} \\
\hline Current oil price $\left(P_{0}\right)$ & \multicolumn{2}{|l|}{$\$ 36.31 /$ barrel } \\
\hline Volatility $(\sigma)$ & \multicolumn{2}{|c|}{ Triangular, $(\min$, likeliest, $\max )=(0.20,0.258,0.35)$} \\
\hline Reversion speed $(\eta)$ & \multicolumn{2}{|c|}{ Uniform, $(\min , \max )=(0.09,0.25)$} \\
\hline Jump frequency $(\lambda)$ & \multicolumn{2}{|l|}{0.125} \\
\hline Jump size $(\Phi)$ & \multicolumn{2}{|c|}{ Probability distribution function in Figure 1} \\
\hline Upper cutoff of oil price & \multicolumn{2}{|l|}{$\$ 200 /$ barrel } \\
\hline \multicolumn{3}{|l|}{ Technical uncertainty } \\
\hline STOOIP (million barrels) & \multicolumn{2}{|l|}{ Lognormal $(1500,300)$} \\
\hline Recovery factor (\%) & \multicolumn{2}{|l|}{$\mathrm{N}(35,2.5)$} \\
\hline Well rate (thousand barrels/day) & \multicolumn{2}{|l|}{$\mathrm{N}(10,3)$} \\
\hline Discount factor in decline phase $(\%)$ & \multicolumn{2}{|l|}{$\mathrm{N}(10,1.2)$} \\
\hline Facility cost (million dollars) & $\begin{array}{c}\text { Maximum rate } \\
\text { (thousand barrels/day) } \\
\leq 50 \\
100 \\
150 \\
200 \\
250 \\
300 \\
300+\end{array}$ & $\begin{array}{c}\text { Cost } \\
\text { (million dollars) } \\
550 \\
750 \\
900 \\
1100 \\
1300 \\
1600 \\
2000\end{array}$ \\
\hline Drilling cost/well & \multicolumn{2}{|l|}{35 million dollars } \\
\hline Operating cost (\$/barrel) & \multicolumn{2}{|l|}{5} \\
\hline Inflation rate $(\% /$ year $)$ & \multicolumn{2}{|l|}{2.5} \\
\hline Working interest (\%) & \multicolumn{2}{|l|}{100} \\
\hline
\end{tabular}

The economic evaluation result is summarized in Table 4 and shown in Fig. 6, with which Fig. 6a represents the histogram of IRR and Fig. $6 \mathrm{~b}$ shows the histogram of NPV with a discount rate of $10 \%$ p.a. The averaged revenue is expected to be around 35 billion dollars and the worst-case value is 3 billion dollars. The range of the NPV@10\% and that of IRR, which refers to the difference between maximum and minimum value, are 16,325 million dollars and $82.5 \%$, respectively. Most of the NPVs with a $10 \%$ p.a. discount rate are positive so that the possibility of undertaking the project, given the hurdle rate of $15 \%$, is $95.3 \%$. The result implies that the petroleum project in this study is currently worth developing and that the risk of loss is relatively small, even though an uncertain environment is considered.

On the other hand, the integration of the price, the reservoir properties, and the contractual terms generated an interesting result, as shown in Figs. 7 and 8. Fig. 7a shows the distribution of the ratio of the NPV to the revenue, and Fig. $7 \mathrm{~b}$ shows the histogram of the revenue, both with a $10 \%$ p.a. discount rate. Fig. 8 is the plot of the reserve vs. IRR. As shown in Fig. 7a, the ratio rises in proportion to the revenue. However, the finding is biased due to the difference in the revenue data of Fig. 7b. Thus, we are able to mention that the contractual effect reduces the actual contractor's profit to around $15 \%-26 \%$ of total revenue. This point can be understood better by referring to Fig. 8 , wherein a larger reserve does not result in a greater profit. The larger the reserve is, the greater the cost will be and the more the government takes on the basis of the PSC. The integration causes divergence in contrast with conventional studies that feature strong convergence.

The correlation coefficients between the input 
Table 4 Summary of statistical results

\begin{tabular}{|c|c|c|c|c|}
\hline & $\begin{array}{c}\text { Revenue@0\% } \\
\text { (million dollars) }\end{array}$ & $\begin{array}{l}\text { Revenue@10\% } \\
\text { (million dollars) }\end{array}$ & $\begin{array}{c}\text { NPV@10\% } \\
\text { (million dollars) }\end{array}$ & IRR(\%) \\
\hline (Mean, stdev) & $(35054,16074)$ & $(13972,7338)$ & $(3253,2234)$ & $(34.9,13.0)$ \\
\hline (Min, $\max$ ) & $(3315,126642)$ & $(543,55325)$ & $(-1461,16324)$ & $(-4.3,78.2)$ \\
\hline Skewness & 1.05 & 1.13 & 1.03 & 0.39 \\
\hline Kurtosis & 4.16 & 4.43 & 4.11 & 3.10 \\
\hline
\end{tabular}

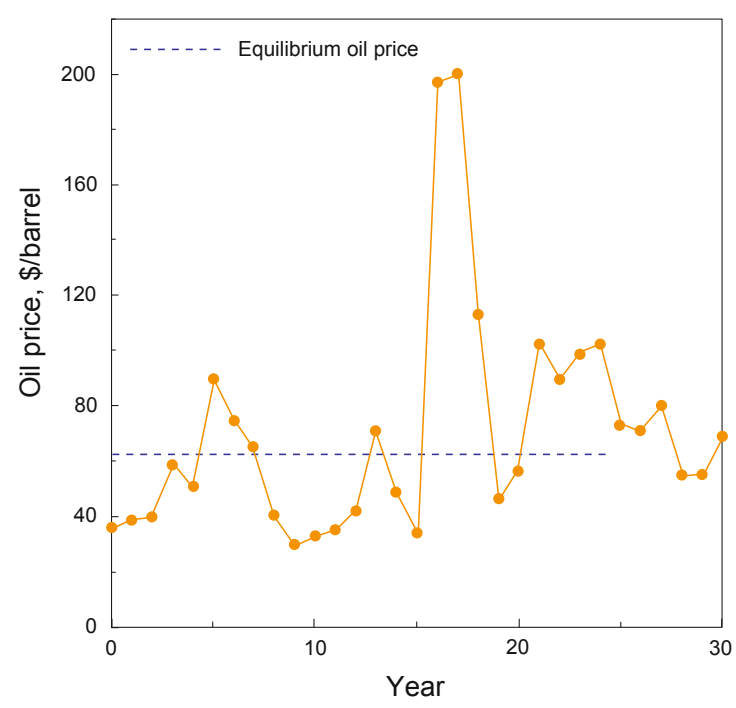

Fig. 4 One example of oil price changes following MRJ

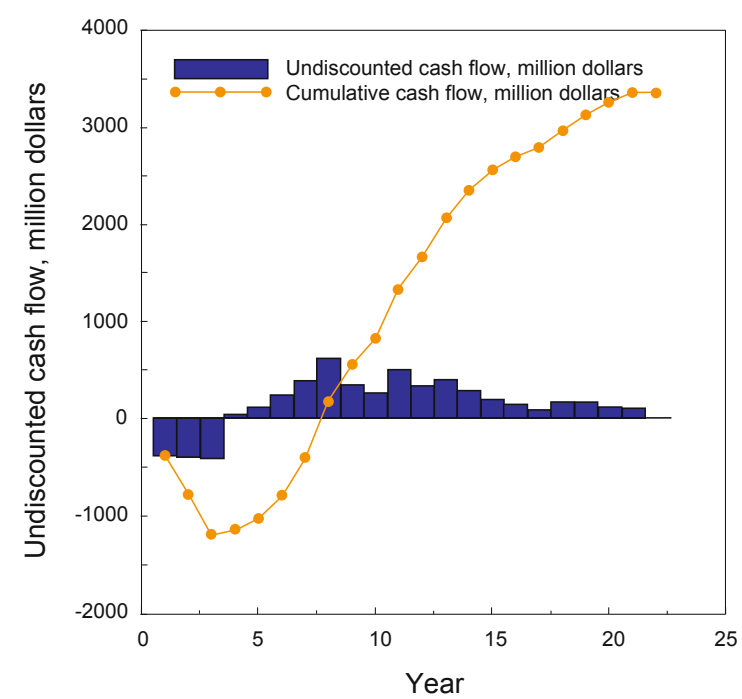

Fig. 5 One example of undiscounted net cash flow from the stochastic approach

stochastic parameters and target results are listed in Table 5. The parameters for price prediction play a minor role in economic evaluation, similar to the case reported by AlHarthy (2007). The oil-price greatly affects the revenue whereas each input parameter in MRJ does not. The reason might be the reversion characteristic of MRJ. Even though
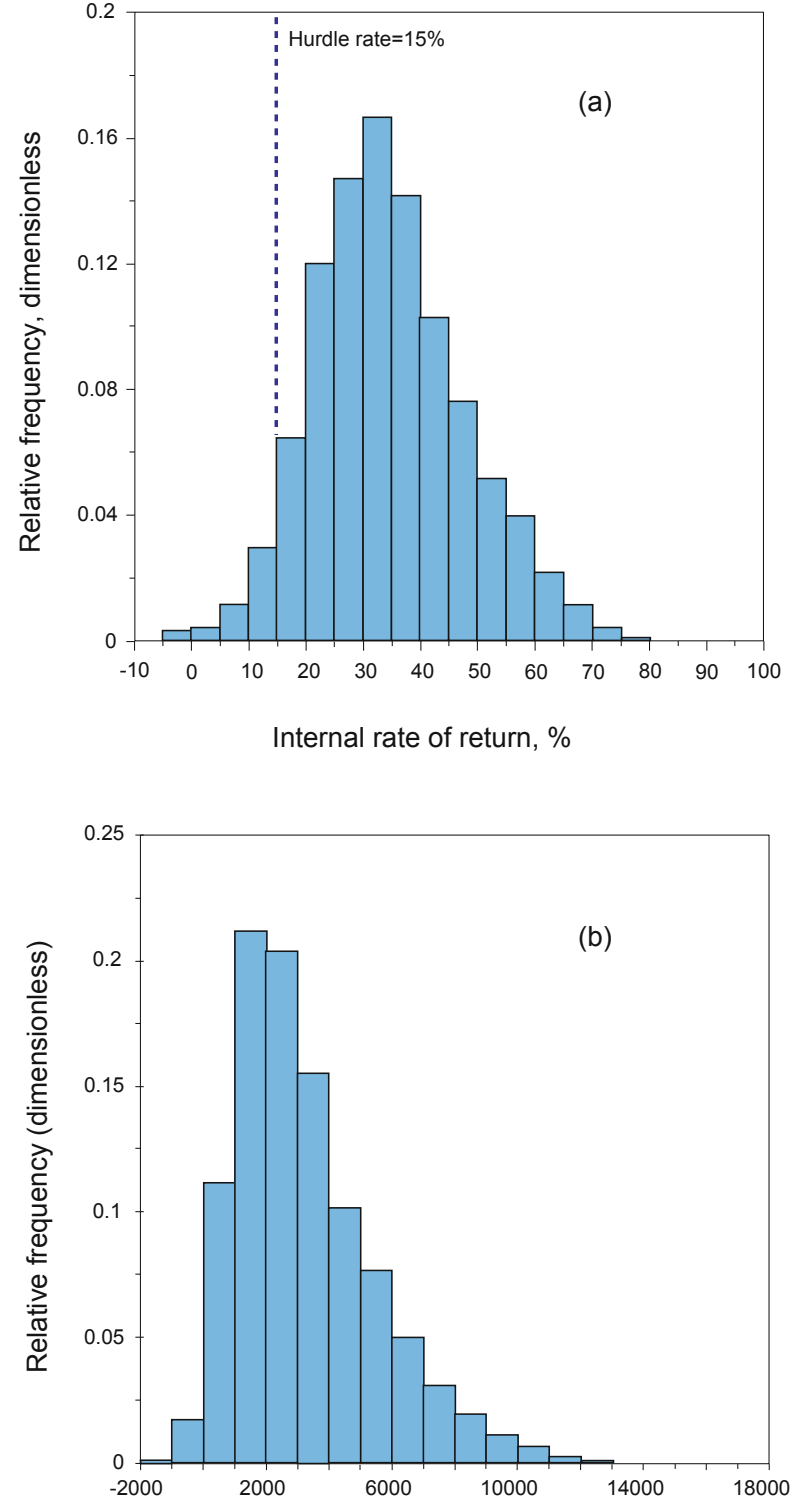

Net present value discounted $10 \%$ per year

Fig. 6 Histogram of (a) internal rate of return and (b) net present value with a $10 \%$ p.a.discount rate

the input parameters help to generate the whole tendency of the price and to yield a wide range of the revenue, they affect merely the development decision. In the viewpoint of technical uncertainty, STOOIP and well rate affect more 
Table 5 Correlation coefficients between input parameters and targets

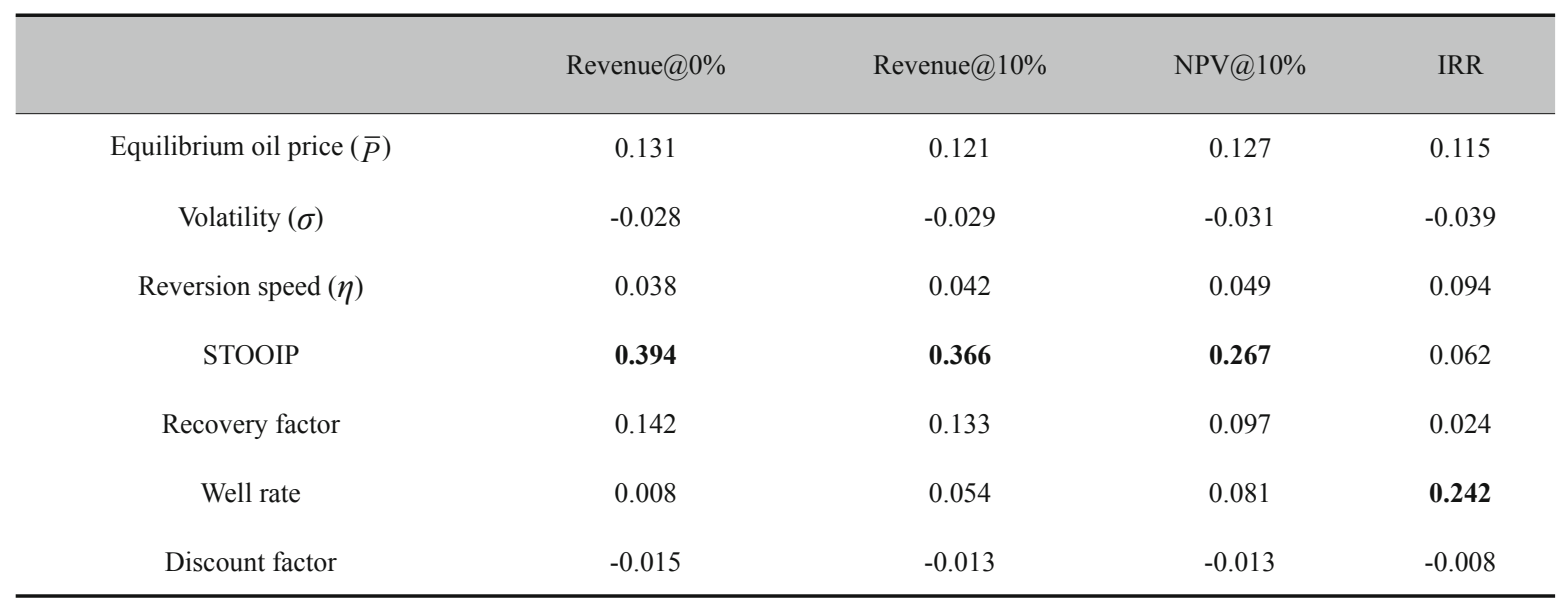

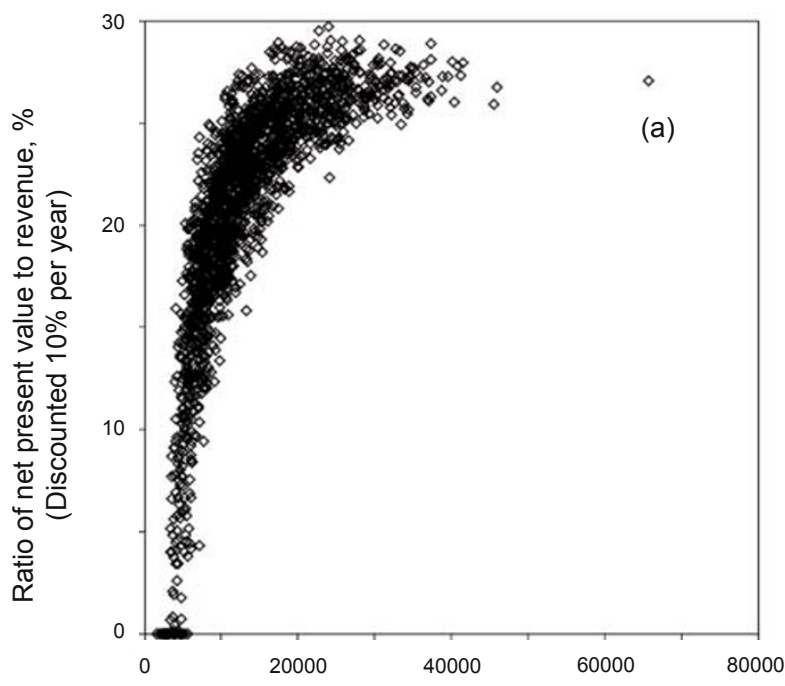

Revenue (Discounted 10\% per year, million dollars)

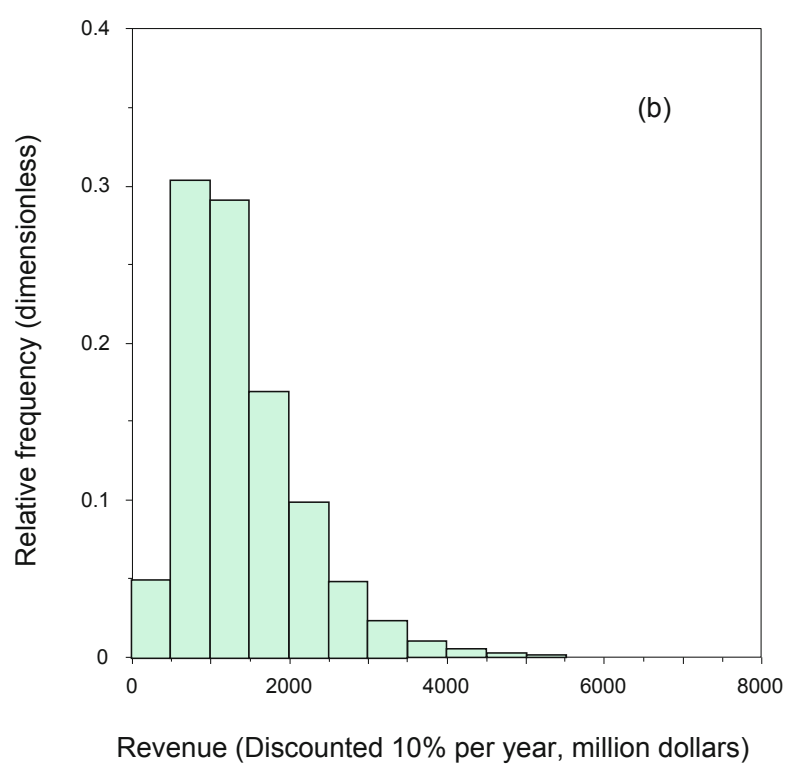

Fig. 7 (a) Distribution of ratio of net present value to revenue and (b) histogram of revenue, both with a $10 \%$ p.a. discount rate the NPV@10\% and IRR respectively than the other inputs Fundamentally, IRR tends to increase as the payback period decreases. The greater the well rate in the early stage, the faster the payback resulting from an increasing IRR.

The developed economic model can be applicable for strategic decision-making to decide whether investment in a development project should be made or not. Various scenarios result in feasible economic solutions regarding the profitability. It confirms that the contractual terms can in no way be negligible. However, the approach cannot capture the effect of managing flexibility according to the business environment since it originates from a discounted cash-flow model. The profitability could be changeable with investor's strategies according to the business environment, management flexibility, financing plan and risk-aversion attitude.

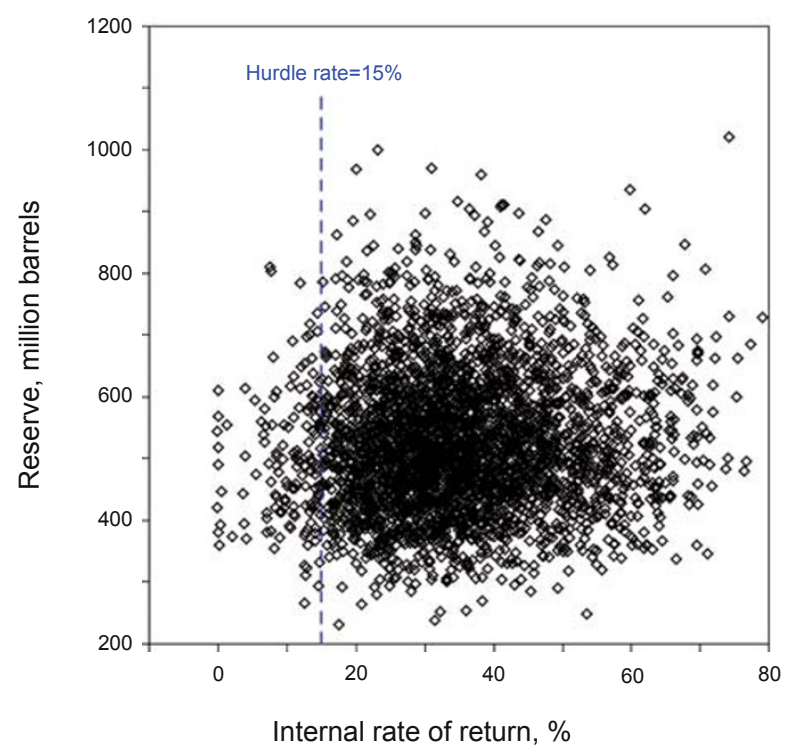

Fig. 8 Plot of reserve vs. internal rate of return under PSC terms

\section{Conclusions}

The integration of market and technical uncertainties is investigated with regard to decision-making in petroleum development under PSC terms. The decision of whether or 
not to develop could be made objectively from the results on the feasible revenue, NPV, and IRR through the use of the stochastic model proposed in this paper. The integration of the two kinds of uncertainty produces the irregular shape in the future cash-flow and reveals that a larger reserve does not always guarantee a greater profit. The stochastic parameters for MRJ affect merely the NPV and the IRR while STOOIP and well rate influence the profit. The article confirms that a lot of information for uncertain variables and contractual terms should be considered to accomplish the reliable economic evaluation of individual petroleum development.

\section{References}

Al-Harthy M H. Stochastic oil price models: comparison and impact. The Engineering Economist. 2007. 52: 269-284

Begg S H and Smit N. Sensitivity of petroleum economics to uncertainty in type and parameters of oil price models. SPE 110812. Presented at the 2007 SPE Annual Technical Conference and Exhibition, 11-14 Nov. 2007, Anaheim, US

Dias M and Rocha K. Petroleum concessions with extendible options using mean reversion with jumps to model oil price. Presented at the 3rd Annual International Conference on Real Options, 6-8 June
1998, Wassenaar, Leiden, Netherlands

Dixit A K and Pindyck R S. Investment under Uncertainty. NJ: Princeton University Press. 1994

EIA. Annual Energy Outlook 2008. US.: Energy Information Administration (http://www.eia.doe.gov). 2008

Hultzsch P, Lake L W and Gilbert R B. Uncertainty estimation through the life of the field. Energy Exploration \& Exploitation. 2008. 26(3): 175-195

Johnston D. International Petroleum Fiscal Systems and Production Sharing Contracts. Oklahoma: PennWell. 1994

Kodukula P and Papudesu C. Project Valuation Using Real Options: A Practitioner's Guide. Florida: J. Ross Publishing. 2006

Olsen G T, Fariyibi F L, Lee W J and McVay D A. Price uncertainty quantification models advance project economic evaluations. SPE 94610. Presented at the 2005 SPE Hydrocarbon Economics and Evaluation Symposium, 3-5 April 2005, Dallas, US

Pelet M. Real Options on Petroleum: Geometric Brownian Motion and Mean-Reversion with Jumps. UK: MS Thesis. Oxford University. 2003

Staber S. Futures-based modeling of the oil price for realistic E\&P project valuation. SPE 104082. Presented at the 2006 SPE International Oil \& Gas Conference and Exhibition, 5-7 December 2006. Beijing, China

(Edited by Zhu Xiuqin) 